\title{
Relevance of abiotic criteria used in German lake typology for macroinvertebrate fauna
}

\author{
Armin Zenker • Beate Baier
}

Received: 23 July 2009/Revised: 28 September 2009/Accepted: 5 October 2009/Published online: 19 October 2009

(C) Springer Science+Business Media B.V. 2009

\begin{abstract}
For lake characterisation, top-down typologies are mostly used throughout Europe, including type criteria such as climate, lake area, catchment geology and conductivity. In Germany, a lake typology was applied comprising ecoregion, calcium concentration, Schindler's ratio, stratification type and residence time. However, the relevance of these criteria for the macroinvertebrate fauna has not been conclusively demonstrated till now. Benthic invertebrate community data and related environmental parameters of pristine or near-pristine lakes in Germany were analysed by multivariate analysis
\end{abstract}

Handling editor: K. Martens

A. Zenker $(\bowtie)$

Institute of Ecopreneurship, School of Life Sciences, University of Applied Sciences Northwestern Switzerland (FHNW), Gründenstrasse 40, CH-4132 Muttenz, Switzerland

e-mail: armin.zenker@fhnw.ch

B. Baier

Department of Animal Ecology, Institute of Zoology, University of Hohenheim, Stuttgart, Germany

e-mail: beate.baier@hu.hamburg.de

Present Address:

B. Baier

Department of Water Research, Institute of Hygiene and Environment, Hamburg, Germany techniques to elucidate which environmental parameters are reflected by invertebrate composition. Moreover, benthic invertebrate data were transformed to metrics expressing ecological attributes and species richness (summarising functional composition, diversity and sensitivity measures). Multivariate statistics were used to test whether information relevant to ordination was lost and whether variation decreases using metrics which combine data with ecological attributes. Analysis of lake-type criteria revealed that ecoregions and prevailing substrates were characterized by different taxonomic compositions of macroinvertebrates. In addition, a relationship was found between community composition and lake size. Creating a novel bottom-up lake typology based on ecoregions, lake size and prevailing substrate gives better separation of distinct macroinvertebrate communities and a higher level of homogeneity within groups compared to top-down typology or single environmental parameters alone, both on species and metrics data. Despite some data variation due to methodological differences (e.g. different sampling and sorting techniques) and interannual and seasonal variation in the data set, NMDS ordination presented well-separated groups of bottom-up lake types. Lake types were more precisely separated by species data than by metric data in both top-down and bottom-up typology. However, as information loss from species lists to calculated metrics is marginal, type-specific benthic invertebrate assemblages are reflected both on the species level and on the metric level. Species and 
metric data are both suitable for data ordination, while single environmental parameters affecting macroinvertebrate composition can best be obtained using metrics.

Keywords Bottom-up typology - Ecological lake classification - Invertebrate composition - Metrics · Multivariate analysis

\section{Introduction}

Macroinvertebrate communities vary in time and space in relation to environmental factors (Hämäläinen et al., 2003 (lakes); Robinson \& Jolidon, 2005 (streams); Van de Meutter et al., 2005 (lakes); Trigal et al., 2006 (lakes)). Species diversity depends on both local habitat conditions and regional variables (Stendera \& Johnson, 2005).

Climate, catchment geology and altitude appear to be essential regional factors affecting invertebrate composition (Johnson, 2003; Füreder et al., 2006). For instance, macroinvertebrate species occurrence in lakes in Northern Ireland is associated with lake altitude and catchment geology (Rippey et al., 2002). A number of studies have also shown a relationship between taxonomic composition and lake size (Heino, 2000; Declerck et al., 2005; Hrabik et al., 2005). Typically, species richness is positively correlated to lake size, which can be explained by the fact that larger areas contain more ecological niches. Aquatic communities also respond to water quality parameters and trophic conditions (Brodersen et al., 1998; Dinsmore et al., 1999; White, 2001), whereas these environmental factors mostly depend on human activities (Allen et al., 1999). One of the most important factors influencing the natural variability of lake invertebrates is the substrate composition (White \& Irvine, 2003; Stoffels et al., 2005; Beaty et al., 2006). The macrophyte cover mainly affects the distribution of benthic invertebrates. In most cases a high complexity of macrophytes leads to an increasing density and diversity of invertebrates (Declerck et al., 2005; Heatherly et al., 2005; Rennie \& Jackson, 2005). Generally, high habitat heterogeneity results in great invertebrate diversity (Tolonen et al., 2001).

The interpretation of relationships between numerous abiotic factors is very complicated, because aquatic macroinvertebrate communities respond to multiple environmental gradients and there are many interactions between several variables. For example, land use affects nutrient concentration in lakes (Allott et al., 1998; White, 2001), thus controlling macrophyte cover and abundance of particulate organic matter used by benthic invertebrates as a food resource (Declerck et al., 2005; Beaty et al., 2006).

To develop a monitoring tool for the ecological quality of lakes, it is generally necessary to differentiate between macroinvertebrate impact response and natural variation. Thus ecological assessment and the definition of reference conditions require a previous classification of water bodies (Muxika et al., 2007). To obtain a limited number of types considering only natural variation, a coarse system should be used including the most important non-anthropogenic parameters.

A European top-down typology for shallow lakes was developed by the project ECOFRAME, considering the requirements of the European Water Framework Directive. Using the type criteria climate, lake area, catchment geology and conductivity, 48 ecotypes were described by Moss et al. (2003). Nykänen et al. (2005) tested this scheme for Finnish lakes and postulated subdivisions of ecotypes to separate Finnish lakes. For Northern Ireland, Hale \& Rippey (2002) described seven lake types for water bodies above 0.2 ha including the parameters altitude, catchment geology, lake size and acid neutralising capacity. Kolada et al. (2005) used the abiotic characteristics ecoregion, lake size, catchment geology, Schindler's ratio (ratio of catchment area and lake volume) and stratification type to identify 13 lake types in Poland. However, a thorough refinement of the ECOFRAME typology seems to be necessary to better reflect the variety of lakes in Europe. In each country, other categories might be required to take into account local conditions.

In Germany, a top-down typology developed by Mathes et al. (2005) is currently used to characterise lakes. It is based on ecoregions (Illies, 1978), calcium concentration, Schindler's ratio, stratification type and residence time. According to these criteria, 14 lake types were described for Germany.

In our study, the natural factors that are reflected by the benthic invertebrate fauna were investigated using data from unimpacted or near-natural lakes. The following question was addressed: how many lake types, based on significantly different macroinvertebrate 
communities, can be distinguished in Germany? As transformation of species data into metrics is often reported to result in an information loss, we tested whether lake type-specific communities are also reflected on the metric level. The resulting bottomup typology is finally discussed in comparison to the pre-defined lake types developed by Mathes et al. (2005).

\section{Methods}

Data collection of benthic invertebrates in German lakes

Data on benthic invertebrates and related environmental parameters (736 data sets of 166 lakes and basins) were collected from various institutions (regional environment agencies and research institutions) and stored in a hierarchical Access ${ }^{\circledR}$ (Microsoft Office 2003) database for further data management and analysis. All samples of a lake or basin belonging to one date and a specific lake zone (eulittoral, sublittoral, littoral, profundal) were pooled to one dataset based on individual numbers. To harmonise determination level and to minimise the heterogeneity of species level identification, data were filtered with an 'operational taxa list' describing the level of identification that can be achieved by an experienced limnologist in Germany and neighbouring territories (Haase \& Sundermann, 2004). In most cases, identification of species level is desired for best ecological classification (Resh \& Unzicker, 1975), but species group or genus level was used for those genera that are difficult to identify or that cannot be determined in the larval stage. Genus/family was used for some Diptera groups following Sundermann et al. (2007). For taxa identified at a more precise level, the level given in the 'operational taxa list' was used.

\section{Selection criteria for reference lakes}

Data of unimpaired lakes or basins $>5$ ha with nearnatural benthic communities were selected based on the following quality criteria: exclusively natural lakes, samples taken only from sublittoral or littoral (except eulittoral) zone, at most $10 \%$ agriculture and urban areas and no wastewater treatment plants in the catchment area, no morphological degradation of the shoreline. Thus, 55 data sets of 21 lakes/basins were selected as reference lakes from our database. Alpine and lowland lakes were considered, whereas the low mountain range was not represented by natural, undisturbed lakes. Seasonality of data was not excluded, since macroinvertebrate samples were taken in spring, summer and autumn season.

An a priori lake typology according to Mathes et al. (2005) was allocated to each lake or basin. Topdown typology consisted of specification according to ecoregion, catchment size, calcium concentration and stratification type. For further analysis, several environmental parameters or variables were collected. These parameters were taken into account because we hypothesised that they could influence the natural variability of species community. As additional background data, ecoregion, altitude, lake size, lake volume, mean depth, maximum depth, size and geology of catchment area, stratification type, residence time, dominant substrate and Schindler's ratio were available.

Metric calculation and selection of significant metrics

Recently published statistical analyses support the hypothesis that merging of species data to higher taxonomic levels does not lead to information loss compared to full species-level analysis. This approach of aggregation is called 'taxonomic sufficiency'. Further classical aggregations of species community data are univariate methods such as the metric ShannonWiener index supporting the hypothesis (Khan, 2006).

Under this assumption, we tested whether information was lost for ordination of lake type-specific communities when species data was translated to several metrics and whether attribution to ecological guilds could likewise eliminate sources of variation, especially overemphasis of single species incidences. Based on species data, a set of about 350 metrics was computed in the same Access database where data on benthic invertebrates and related environmental parameters were stored. Further information on single metrics is described in Böhmer et al. (2004) and the AQEM Manual (2002). Metrics were calculated based on species presence, abundance classes and individual numbers. For this purpose, individual numbers were converted into abundance classes and vice versa using the classes defined by Alf et al. 
(1992) and their centre values (class $1=1$; class $2=2-20$, centre 10 ; class $3=21-40$, centre 30 ; class $4=41-80$, centre 60 ; class $5=81-160$, centre 80 ; class $6=161-320$, centre 160 ; class $7=>320$, centre not applicable, set to 320 ).

In preliminary studies of macrobenthos communities in German lakes, nine metrics were determined to have the potential to drive differences among degrees of human impacts (Baier \& Zenker, 2005): number of ETO (Ephemeroptera, Trichoptera, Odonata) taxa, percentage of insect species, percentage of feedingtype predators, percentage of feeding-type sediment feeders, percentage of feeding-type grazers/scrapers, percentage of oligosaprob species, percentage of current preference limno-rheophil, locomotion type sprawling/walking, and percentage of microhabitat preference psammal. A metric selection from macrobenthos communities in streams to distinguish between different impact classes generated similar candidates (Hering et al., 2004), which emphasised our hypothesis that these metrics were in general able to indicate changes in abiotic parameters. Therefore, these 'meaningful' metrics which are ecologically relevant were also selected to describe lake typespecific communities.

\section{Data analysis}

To initially identify single environmental parameters affecting species richness and diversity of benthic communities, the metrics taxon richness, number of ETO taxa, percentage of insect species and Shannon diversity were tested for differences in lake size classes, lake depth classes and size classes of catchment area using analysis of variance (ANOVA) followed by Scheffé's post-hoc procedure. The nonparametric one-way ANOVA using Wilcoxon (Kruskal-Wallis) followed by the Bonferroni-corrected Wilcoxon-Mann-Whitney test was carried out when metrics lacked homogeneity of variance (Levene's test $P<0.05$ ). To test for the differences in metric values between two groups of lakes (two ecoregions, stratification types or prevailing substrates), Student's $t$ test (Levene's test $P>0.05$ ) or Wilcoxon-Mann-Whitney test was used (Levene's test $P<0.05$ ). Comparisons of mean values of metrics were conducted using SPSS 12.0 for Windows (SPSS Inc., Chicago, IL).

In order to scrutinise influences of environmental parameters determining species composition, a matrix with 305 species in 55 plots was generated where abundance scores were not transformed prior to analysis. Rare species and other outliers were not excluded before analysis, but transformation of abundance data to presence-absence was similarly arranged to examine ordination. Non-metric multidimensional scaling (NMDS) was chosen as ordination analysis to assess differences in species composition between lakes. NMDS ordination was selected because of its non-restrictive assumptions (not assuming random sampling, multivariate normality and non-clustering of observations) which are required in mathematical techniques called eigen analysis in, e.g., principal components analysis (PCA) (McGarigal et al., 2000). NMDS was run on species abundance data using a Sørensen distance measurement including varimax rotation, a maximum number of 100 iterations and an instability criterion of $5 \times 10^{-3}$. In addition to the often used Sørensen distance measurement, Jaccard distance was also tested in the case of resulting better ordination. Final stress values for ecological data range between 10 and 20, given that stress is a measure of diversity increase. Reliable values for stress are normally specified in the range between 15 and 10 (McCune \& Grace, 2002).

A multi-response permutation procedure (MRPP) as multivariate analysis is a non-parametric routineindependent of the assumptions of normally distributed data or homogeneous variances-to test the hypothesis of no differences in community composition between two or more groups. This difference may be one of location (differences in mean) or one of spread (differences in within-group distance). More details of MRPP are provided by Mielke (1984). Analysis of similarity (ANOSIM; Clarke, 1993), often used instead of MRPP, is very similar except for applying different test statistics.

For testing species data, we used the Sørensen (Bray Curtis) distance measure and a natural group weighting factor $n(i) / \operatorname{sum}(n(i))$, where $n(i)$ is the number of sample plots in each group and the distance matrix was rank transformed. The Sørensen distance was used as the MRPP distance measure for species data to avoid the influence of outliers (McCune \& Grace, 2002). Both NMDS and MRPP were performed using PC-ORD 4.0 for Windows software (McCune \& Mefford, 1999).

NMDS and MRPP were performed with a reduced matrix of nine 'species' or appropriate metrics in 55 
plots. Metrics data was initially min-max transformed. For the ordination of lakes by metrics data, NMDS was conducted with Euclidian distance measure including varimax rotation, a maximum number of 100 iterations and an instability criterion of $5 \times$ $10^{-3}$. Euclidean (Pythagorean) distance measure was also applied when metrics data was analysed by MRPP. As Euclidean (Pythagorean) and relativised Euclidean distance measure tends to emphasise outliers as compared to Jaccard and Sørensen, it was adequately applied in rank-transformed 'metrics' distance matrices with a natural group weighting factor $n(i) / \operatorname{sum}(n(i))$. In contrast to species abundance data, metrics were interval-scaled between 0 and 1 , where outliers were cut off.

\section{Results}

Single metrics evaluation

The dataset of single metrics derived from species abundance data was initially tested to identify environmental factors reflecting differences in richness and diversity of the invertebrate fauna. This analysis revealed that ecoregions were differentiated by taxon richness ( $t$ test, $T=3.19, P<0.01$ ), number of ETO taxa (Mann-Whitney-U $=58.50$, $P<0.01$ ) and percentage of insect species (MannWhitney-U $=89.00, P<0.05)$. All three averaged metric values mentioned above were higher in alpine lakes $(30.1 \pm 13.2$ taxa, $12.4 \pm 8.1$ ETO taxa and $81.0 \pm 10.1 \%$ insect species) compared to lowland lakes $(16.2 \pm 10.5$ taxa, $4.9 \pm 4.5$ ETO taxa and $50.2 \pm 34.3 \%$ insect species). In general ETO taxa in lowland lakes were dominated by Trichoptera whereas alpine lakes were mainly represented by Ephemeroptera and Trichoptera. The Shannon diversity index did not vary statistically significant between ecoregions (Fig. 1).

Community structure also depends on lake size (Fig. 2). Differences in taxon richness (KruskalWallis, $\left.\chi_{(3)}^{2}=9.81, P<0.05\right)$, percentage of insect species (Kruskal-Wallis, $\chi_{(3)}^{2}=15.56, P<0.01$ ), and Shannon diversity (Kruskal-Wallis, $\chi_{(3)}^{2}=$ 10.61, $P<0.05)$ were significant among all lake size
Fig. 1 Box plots of taxon richness (a), number of ETO taxa (b), percentage of insect species (c), and Shannon diversity (d) for the two ecoregions Alps and Northern Lowlands (box 25 th and 75th quantiles, whiskers interquartile range, line marks the median.) $* P<0.05$; ** $P<0.01$; Student's $t$ test $(\mathbf{a}, \mathbf{d})$ and Wilcoxon-Mann-Whitney test $(\mathbf{b}, \mathbf{c}) ; n$ number of samples, open circle outlier
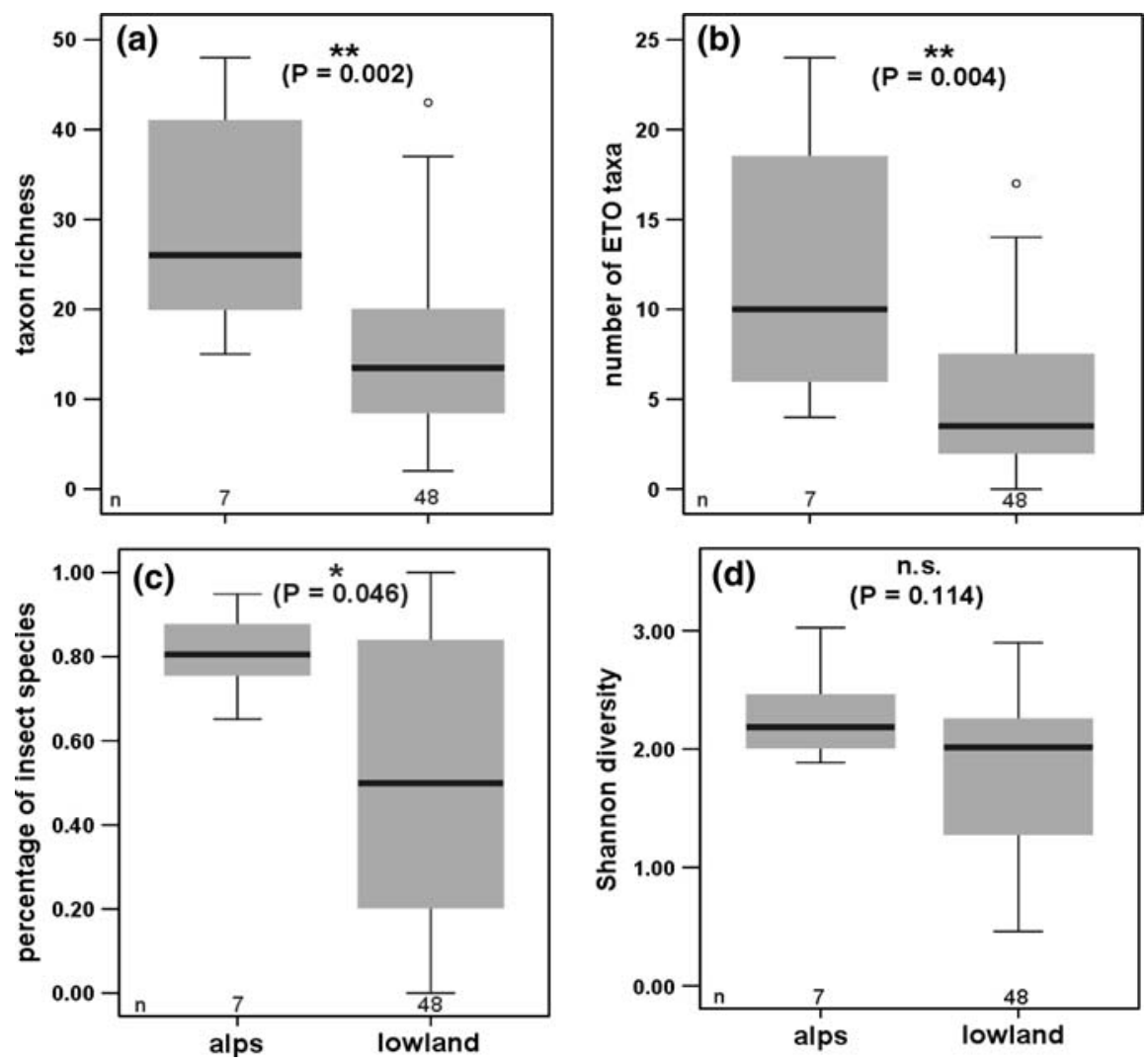
Fig. 2 Box plots of taxon richness (a), percentage of insect species (b), and Shannon-diversity (c) for lake size classes (box 25th and 75th quantiles, whiskers interquartile range, line marks the median.). Boxes with different letters are significantly different at $P<0.05$ (Kruskal-Wallis followed by the Bonferonicorrected Wilcoxon-MannWhitney test). $n$ number of samples, asterisk extreme value, open circle outlier
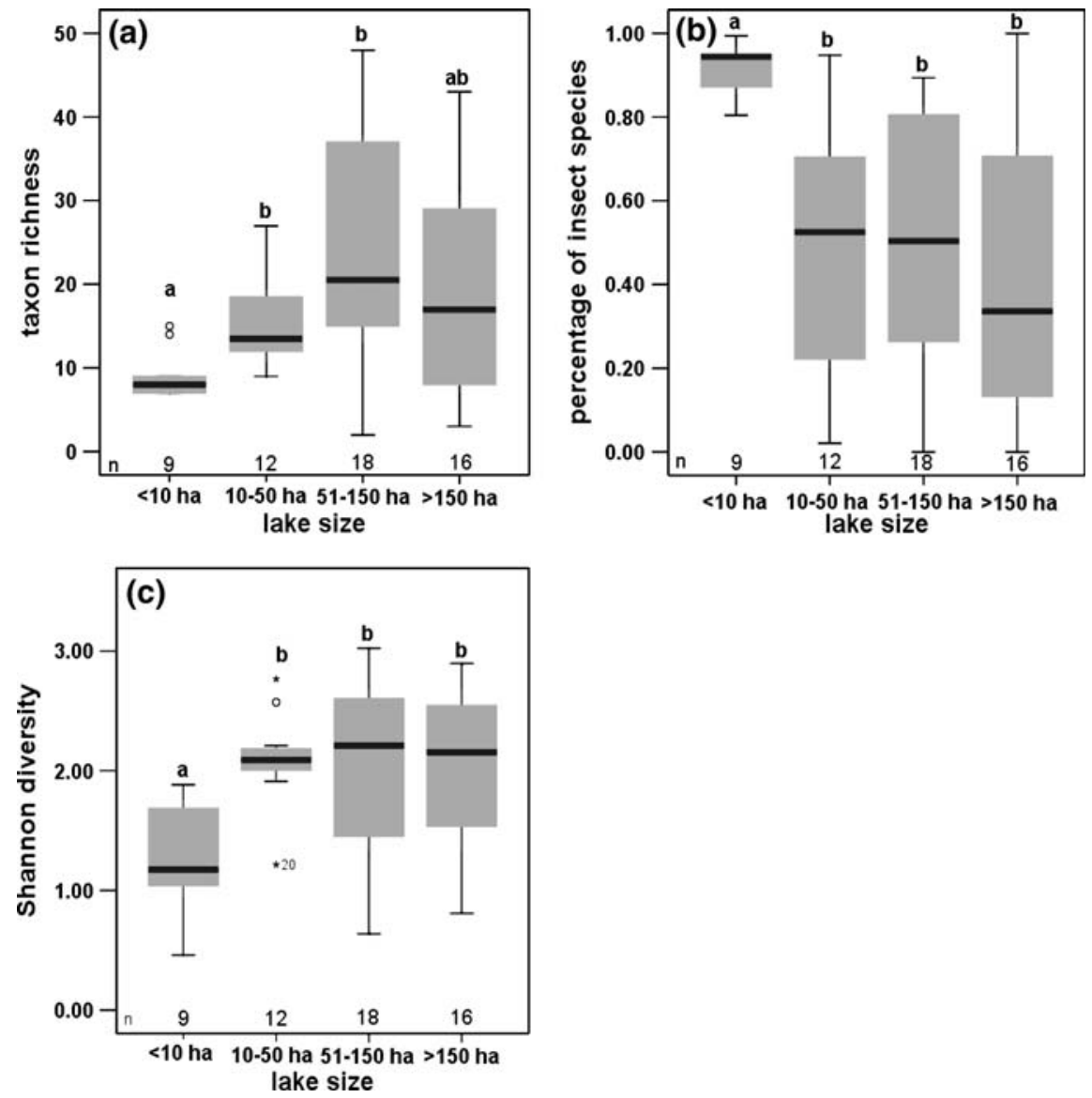

classes. The lowest taxa richness and diversity was recorded in small lakes $<10$ ha with $9.33 \pm 3.04$ and $1.28 \pm 0.50$, respectively, whereas percentage of insect species in small lakes $(9.14 \pm 0.65 \%)$ were significantly higher compared to lakes $>10$ ha.

The percentage of insect species also varied significantly between organic and sand-dominated lakes ( $t$ test, $T=2.75, P<0.01$ ). In general sanddominated lakes were inhabitated by more larval insect species $(68.9 \pm 34.6 \%)$ than organic-dominated lakes $(44.2 \pm 30.5 \%)$. For instance the caddisfly Athripsodes bilineatus (Linnaeus), the mayfly Leptophlebia vespertina (Linnaeus) and the chironomid Ablabesmyia longistyla (Fittkau) only appeared in sand-dominated lakes and also Tanytarsini were more abundant in these lakes. In contrast, the prevailing substrate revealed no effects on taxa richness, number of ETO taxa and diversity (data not shown).

Of the remaining factors, neither lake depth, nor size of catchment area, nor stratification type was significant with respect to species richness and diversity. Thus, all tested factors suggested that macroinvertebrate community composition in unimpacted lakes is influenced by ecoregion, reflecting altitude and climate, lake size and prevailing substrate, whereas lake depth, catchment area and stratification type demonstrated no effects on the natural variability of lake invertebrates inhabiting the littoral and sublittoral zones.

These results prompted us to draw up a bottom-up typology for German lakes based on the macroinvertebrate fauna derived from ecoregion (alps or lowlands), lake size ( $<$ or $>10 \mathrm{ha}$ ), and prevailing substrate (sand or organic) in contrast to the top-down typology developed by Mathes et al. (2005).

NMDS ordination of lake samples overlay by top-down and bottom-up typology

NMDS ordination was first overlaid by the suggested bottom-up lake types and the top-down lake types 
defined by Mathes et al. (2005). Bottom-up and topdown lake types were both well discriminated by species and metrics data. Ordination of lake samples in Fig. 3C (metric level) was rotated by $90^{\circ}$ compared to Fig. 3A (species level). When Fig. 3A and C were compared, NMDS ordination generated larger distance measures taking species level data into account (Axis 2), even though an increased ordination area did not lead to a better separation of lake samples. Some slight overlaps between clusters of sandy lowland and alpine lakes larger than 10 ha existed in metrics data ordination.

In Fig. 3A, Axis 2 represented a gradient from the cluster 'small sandy lowland lakes', to the cluster 'larger sandy alpine lakes' along to the cluster 'larger sandy lowland lakes', whereas the same gradient was present in Fig. 3C on Axis 1. Organic lowland lakes were more or less dispersed in one-third of the graph. In Fig. 3C, the two clusters 'small sandy lowland lakes' and 'larger sandy alpine lakes' formed a distinct
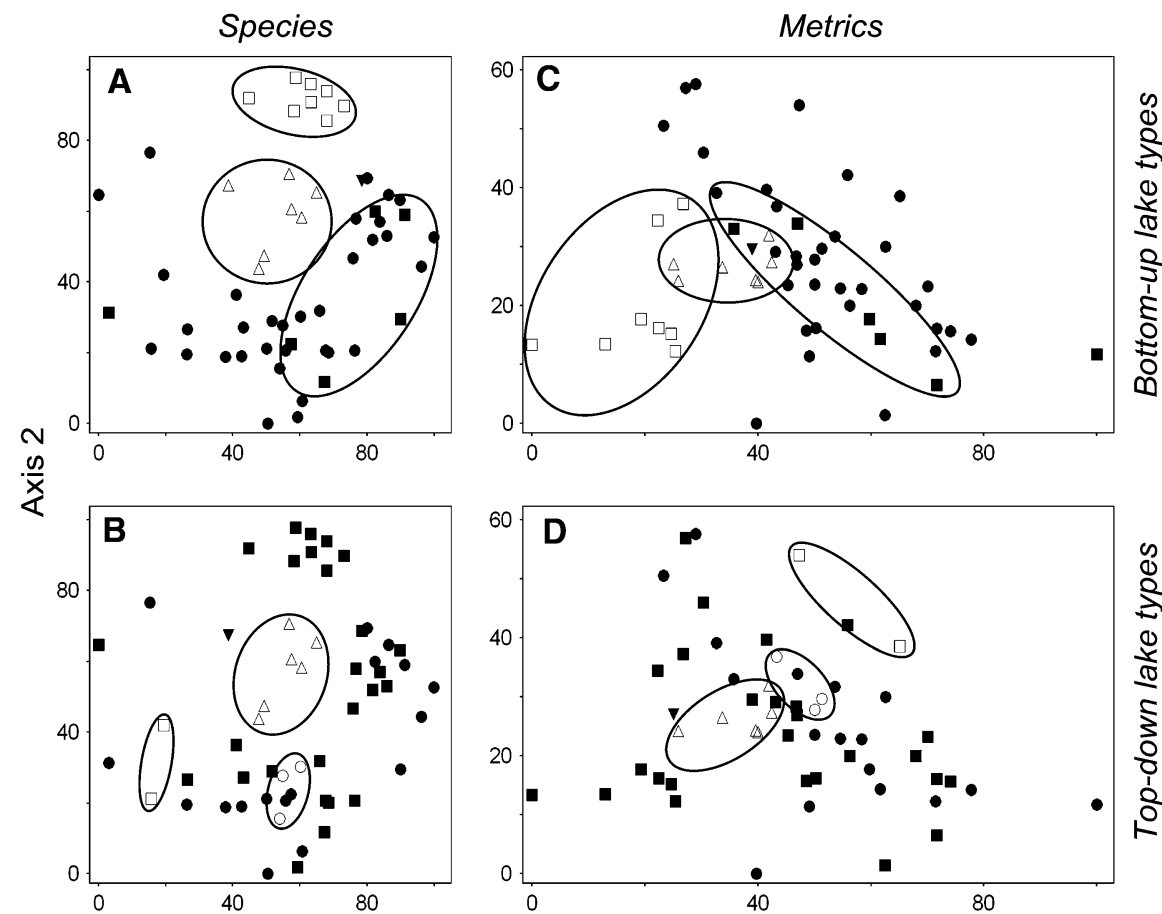

Axis 1

Bottom-up lake types (A and C) :

$\boldsymbol{\nabla}=$ no lake type specification available, $\Delta=$ alpine, sandy lakes ( $>10$ ha lake surface area),

- = sandy lowland lakes (>10 ha), $\square=$ sandy lowland lakes (<10 ha), $\bullet=$ organic lowland lakes (>10 ha)

Top-down lake types (B and D):

$\boldsymbol{\nabla}=$ calcareous lakes of the alpine foothills (type 2), $\Delta=$ calcareous alpine lakes (type 4),

- = dimictic lowland lakes (type10), $\square=$ polymictic lowland lakes (type 11),

- = dimictic lowland lakes (type 13), o = polymictic lowland lakes (type 14).

Fig. 3 Two-dimensional MDS ordination on species (A and B) and metric level (C and D) overlaid by the suggested bottom-up lake types (A and $\mathbf{C}$ ) and the top-down lake types by Mathes et al. (2005) (B and D). Symbols correspond to the following bottom-up lake types: inverted filled triangle no lake type specification available, open triangle alpine, sandy lakes $(>10$ ha lake surface area), filled square sandy lowland lakes $(>10$ ha), open square sandy lowland lakes ( $<10$ ha), filled circle organic lowland lakes ( $>10$ ha) and the top-down lake types: inverted filled triangle calcareous lakes of the alpine foothills (type 2), open triangle calcareous alpine lakes (type 4), filled square dimictic lowland lakes (type 10), open square polymictic lowland lakes (type 11), filled circle dimictic lowland lakes (type 13), open circle polymictic lowland lakes (type 14). Ordination on species level by Bray-Curtis distance measure based on abundance data of 305 taxa in 55 lake sample plots (stress value $=19$ ), and on metric level by Euclidian distance measure based on data of nine metrics calculated from these sample plots (stress value $=15$ ) 
group, particularly by high metric values of 'percentage of insect species' and 'percentage of microhabitat preference psammal'. Typical insect species of small sandy lowland lakes were Microtendipes sp., Molanna angustata (Curtis) and Sialis lutaria (Linnaeus), whereas Athripsodes bilineatus and Paraleptophlebia sp. were exclusivly found in larger sandy alpine lakes. In contrast, Tinodes waeneri (Linnaeus), Lype phaeopa (Stephens), Agraylea sp. and Ceraclea sp. never appeared in sandy lakes. With the exception of one lake, where no lake typology was possible because of a missing substrate specification, all other lakes could be assigned by bottom-up typology.

The ordination of top-down typology lake types in Fig. 3B (by species data) and 3D (by metrics data, rotated compared to Fig. 3B) characterised three distinct clusters, which were separated more clearly by species data in Fig. 3B along Axis 1 than by metrics data along Axis 2. The one sample of 'calcareous lakes of the alpine foothills' was also well separated on species level (Fig. 3B), while the same lake type was clustered to "calcareous lakes of Alps' on metric level.

In Fig. 3B a gradient along Axis 1 is represented by lakes from the cluster 'polymictic lowland lakes with a great catchment area (type 11)', to the cluster 'calcareous lakes of Alps', along to the cluster 'polymictic lowland lakes with a small catchment area (type 14)'. However, dimictic lowland lakes formed distinct clusters neither on species level nor on metric level.

Non-metric multidimensional scaling (NMDS) attempts to minimize the square root of the ratio of squared differences between a monotonic transformation of the calculated distances and the plotted distances and the sum of the plotted distances squared, which is expressed by the stress value. The stress value for the two-dimensional ordination in Fig. 3 was 15 for metrics data and 19 for species data.

NMDS ordination of lake samples overlay by ecoregion and prevailing substrate

In a second step, NMDS ordination was overlaid by ecoregions (Fig. 4B on species level and D on metric level) and prevailing substrate (Fig. 4A on species level and $\mathrm{C}$ on metric level). These graphs displayed comparable patterns both on metrics and species data. The majority of samples originated from the lowlands, whereas some sites were located in the alpine
Fig. 4 Two-dimensional MDS ordination on species (A and B) and metric level $(\mathbf{C}$ and $\mathbf{D})$ overlaid by prevailing substrate type (A and $\mathbf{C}$ ) and ecoregion (B and D). Substrate types: inverted filled triangle no substrate specification available, open triangle sand, filled square organic substrate. Ecoregions: inverted triangle alps, open triangle lowland.

Ordination on species level by Bray-Curtis distance measure based on abundance data of 305 taxa in 55 lake sample plots (stress value $=19$ ), and on metric level by Euclidian distance measure based on data of nine metrics calculated from these sample plots (stress value $=15$ )
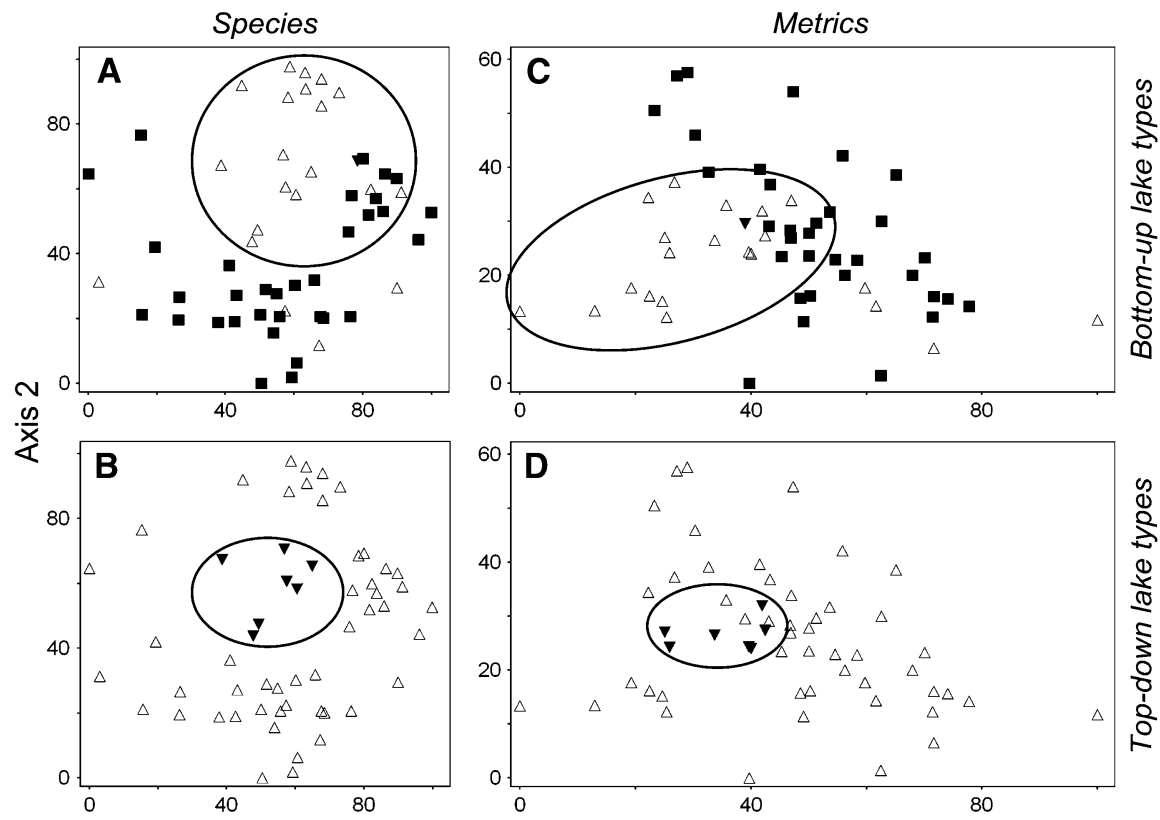

Axis 1

Substrate types (A and C): $\mathbf{\nabla}=$ no substrate specification available, $\Delta=$ sand, $\boldsymbol{\square}=$ organic substrate.

Ecoregions $(\mathrm{B}$ and $\mathrm{D}): \boldsymbol{\nabla}=$ alps, $\Delta=$ lowland. 
region. These samples form a clearly separated group and can easily be distinguished from lowland samples on metrics and species level (see Fig. 4B, D).

As already appeared in the graphs of Fig. 3, with the exception of one lake where substrate specification was missing, all other lakes could be assigned to a specific substrate. In spite of some overlaps between organic and sand-bottom samples, lakes with organic substrates were distinctly separated from lakes with sand-dominated substrates. This demonstrated a strong relationship between community composition and the prevailing substrate (see Fig. 4A). While there were some outliers of alpine samples on species level, a similar picture appeared for NMDS ordination on metrics level (see Fig 4C). The stress value for the twodimensional ordination in Fig. 4 was 15 for metrics data and 19 for species data.

No clear gradient could be observed in lake depth, stratification type and catchment size (data not shown). Neither lake depth nor stratification type nor catchment size seemed to be an obvious determinant of the benthic invertebrate communities in lakes.

\section{Multi-response permutation procedure (MRPP)}

For the non-parametric multi-response permutation procedure (MRPP), all data were used except two single data sets. In one set, only one record was available for top-down lake type 'calcareous lakes of alpine foothills (type 2)' and the other single record featured no information of the prevailing substrate. The latter data set was also excluded in MRPP when bottom-up lake types-defined by lake size, ecoregion and prevailing substrate-were tested on their chance-corrected within-group agreement.

The analysis indicated best separation between lakes $<$ and $>10$ ha $(A=0.12, P<0.001$ on metric level and $A=0.18, P<0.001$ on species level) with a high homogeneity within each group. In spite of some overlaps between organic and sand-bottom samples $(A=0.08, P<0.001$ on metric level and $A=0.10, P<0.001$ on species level) as well as between samples from alpine and lowland lakes $(A=$ $0.05, P<0.005$ on metric level and $A=0.04$, $P<0.01$ on species level), consideration of all these environmental factors gave evidence of bottom-up lake types in Germany (Fig. 3A, C).

By summarizing lake size, prevailing substrate and ecoregion to a newly created bottom-up lake typology, homogeneity within groups increased when compared to single parameters such as lake size alone. Metric data (summarizing functional composition, diversity and sensitivity measures) (see Fig. 3C) as well as species composition (see also Fig. 3A) differed significantly between these lake types (MRPP, $A=0.17$, $P<0.001$ and $A=0.26, P<0.001$, respectively). 'Alpine, sandy lakes' representatives of alpine lakes samples could be separated clearly from other samples. A further subcategorisation of alpine lakes is currently not feasible, as all available data samples derived from larger sand-dominated lakes except one further sample of a small alpine lake ( $\sim 6 \mathrm{ha}$ ) which was equally sand-dominated. The rather well-separated type 'sandy lowland lakes ( $<10 \mathrm{ha})$ ' consisted of lowland lakes with an area of at most ten hectares and sand-dominated substrates. The cluster group 'sandy lowland lakes (>10 ha)' and 'organic lowland lakes (>10 ha)' included both lowland lakes with an area of at least ten hectares where 'sandy lowland lakes (>10 ha)' comprised the majority of samples from sand-dominated lakes and 'organic lowland lakes (>10 ha)' represented organic samples from lowland lakes with some overlaps to 'sandy lowland lakes (>10 ha)'. This discrimination of suggested bottomup lake types is more apparent on the species level than on the metric level. In particular, the separation of alpine lakes is less obvious on the metric level.

Clustering the sample plots in six groups by topdown lake typology referring to Mathes et al. (2005) provided a less clear separation between groups with a lower level of homogeneity within groups (MRPP, $A=0.08, P<0.005$ on metric level and $A=0.12$, $P<0.001$ on species level) compared to bottom-up typology.

\section{Discussion}

Abiotic factors significantly affecting lake typology

Multivariate analysis of macroinvertebrate data on 21 reference lakes in Germany revealed that the benthic community structure in the littoral and sublittoral zone depends on ecoregion, prevailing substrate and lake size. The ecoregion concept considers the distribution limit of species and subsumes regional factors like climate, longitude, latitude and altitude 
into one geographical component that can be defined simply. A number of studies demonstrated that natural variability of macroinvertebrates is influenced by ecoregion (e.g. Moog et al., 2004). For instance Allen et al. (1999) have shown that benthic invertebrate assemblages of upland lakes in harsh climates can be distinguished from those of lowland lakes in milder climates. The strong relationship between altitude and invertebrate composition has also been demonstrated within an ecoregion (Lafrancois et al., 2003; Füreder et al., 2006). According to Illies (1978), three ecoregions are defined for Germany: the Alps including the alpine foothills, the lower mountain ranges and the northern lowlands. Our ordination analyses based on invertebrate community structure confirmed the topdown typology regarding to the two ecoregions Alps and northern lowlands. A further separation of alpine lakes and lakes of the alpine foothills is not feasible at the moment. The mountainous region of Germany was not considered in our study, as natural, undisturbed lakes were not available there.

Even more important than ecoregion are habitat patterns for taxonomic and structural composition (Johnson \& Goedkoop, 2002; Stoffels et al., 2005). Variations in habitat structure, particularly in substrate diversity, leads to a complex benthic community, because species differ in their habitat preference. When White \& Irvine (2003) compared benthic communities from different habitats of 22 lakes, benthic assemblages were more homogenous within a substrate type than within lakes. Significant differences in invertebrate composition of sandy and organic habitats were demonstrated by Barton (1988). In our study, the prevailing substrate was sufficient to discriminate among lake types, although heterogeneous substrate composition and different degrees of macrophyte cover may lead to a less clear separation of undisturbed lakes. All samples of the tested dataset derived either from sand-dominated or organic lakes, thus discrimination from stony or gravel-dominated lakes could not be tested yet. The well-separated group of small lowland lakes ( $<10$ ha) consists of sanddominated lakes only. Therefore, the relevance of the prevailing substrate still has to be demonstrated for this lake size class.

With respect to lake size, our results correspond well to findings of Moss et al. (2003) demonstrating that ecological characteristics of lakes with areas between 50 and 10,000 ha do not differ significantly.
On the other hand Heino (2000) as well as Studinski \& Grubbs (2007) have demonstrated that taxa richness, especially of small lakes, increases with lake size (0.6-32 ha and 0.02-0.1 ha, respectively). In this study, only lakes $<10$ ha formed a clearly separated group, possibly due to less complex habitat conditions in such small lakes. A further separation of lakes from 10 to 450 ha did not arise from our data. These results confirmed the top-down typology without considering lake size classes, which was developed by Mathes et al. (2005) for German lakes $>50$ ha.

Furthermore our data pointed out that the benthic community structure of unimpacted lakes was not affected by catchment size, lake depth or stratification type. Although land use of catchment area has shown strong relationships to community composition of macroinvertebrates (Allen et al., 1999; Collier, 2008), lake type criteria should be independent of anthropogenic disturbances. Catchment area alone, as well as the ratio of catchment area and lake volume (Schindler's ratio) which was used in German topdown, was not reflected by reference macroinvertebrate communities either on species level or on metric level. It stands to reason that if the catchment is unimpaired its size does not matter.

Even though a number of studies provide evidence of a significant association between lake zone and the taxonomic and functional structure of the invertebrate fauna (e.g. Lindegaard, 1992; Johnson, 1998), lake zonation is dependent on the extension of the euphotic zone and not on absolute lake depth. Consequently, lake depth could not be detected as a determinant of the benthic invertebrate fauna. When the macroinvertebrate community was sampled for our data set, invertebrates were mainly gathered from littoral to sublittoral zones as allowed by our data selection criteria, and thus differences in the benthic community dependent on lake zone were minimized. Since littoral and sublittoral zones are not affected by lake stratification, the structure of invertebrate assemblages revealed no relationship to stratification type. At this point, our results could not confirm the top-down typology which considers stratification type as a relevant type criterion.

The littoral zone of natural lakes extends to considerable depth and, in contrast to absolute lake depth, sampling depth within a lake zone likewise influences macroinvertebrate composition (Barton, 
1988; Ali et al., 2002; Stoffels et al., 2005). It was presumed that data variation in our data set could be explained by different sampling depth, among other reasons.

Another recommended-type criterion is catchment geology (Moss et al., 2003), as the dependent parameter total water hardness has been demonstrated to be an important environmental factor corresponding to invertebrate composition (Heino, 2000). The German top-down typology uses two classes of calcium concentrations $(<15 \mathrm{mg} \mathrm{Ca} / \mathrm{l}$ and $>15 \mathrm{mg} \mathrm{Ca} / \mathrm{l})$ to separate calcareous and siliceous lakes. However, in Germany there are only a few natural, unimpaired siliceous lakes, of which we received no data so far. All samples of this study were derived solely from calcareous lakes. Hence the bottom-up classification system is only valid for calcareous lakes up to now.

Sources of data variation

In addition to spatial variability mentioned above, seasonal and interannual variation in invertebrate composition could possibly have affected our results. Sampling in different seasons and years may cause a different dominance structure in the benthic fauna and different frequencies of several species (e.g. White, 2001; Trigal et al., 2006). These findings are inconsistent with our data where sampling of alpine lakes, for example, occurred in spring, summer and fall, and furthermore in three different years. This group of alpine lakes was clearly separated from lowland lakes.

Different sampling techniques (Ekman-Birge bottom sampler or dip net sampling) and also different sorting techniques strongly influence findings of an investigation (Lafrancois et al., 2003; Garcia-Criado $\&$ Trigal, 2005). In the group of sand-dominated lakes, four outliers can be recorded on the species level as well as on the metric level, caused by a different sampling technique (see Fig. 4A, C). The identical data records lead to an increased variation in samples of bottom-up lake type 'larger sandy lowland lakes' (see Fig. 3A, C). In addition, variation in organic-dominated lakes may originate mainly from a different sampling technique (see Fig. 4A, C).

In spite of methodological differences as well as spatial and temporal variation among data sets, moderate final stress values of the two-dimensional NMDS plots ranging from 15 to 19 indicate good fit between original distribution of similarity values and the NMDS plot (Clarke \& Warwick, 2001). Acceptable NMDS solutions generally feature stress values less than 20.

Similarly our MRPP test statistic which describes the separation between tested groups presents high to moderate $A$ values combined with low probability values $P$, showing that $A$ values are statistically significant. The $A$ value as a descriptor of withingroup homogeneity reached its highest values when newly created bottom-up lake types were tested. According to maximum $A$ values both on metric level and on species level, highest homogeneity within groups was attained in bottom-up typology.

In conclusion, our study demonstrates that a bottom-up typology is more feasible than a top-down typology. The a priori classification of German lakes developed by Mathes et al. (2005) was not able to reflect variability in invertebrate community structure. Both ecoregion and habitat variables are proper predictors of benthic community structure. In particular, the prevailing substrate is related to macroinvertebrate composition and should therefore be urgently considered in a lake typology.

Minor information loss from species to metrics data

Species abundances do not depend only on amongsite variation due to natural environmental factors. As mentioned above, within-site and temporal variability (within-year and among years) as well as methodological differences, which may be regarded as background noise, are also responsible for natural variation in species composition (e.g. Johnson, 1998). In contrast, biological traits, e.g. the relative abundance of certain feeding types, integrate ecological information in a reasonable way and reveal a lower natural variability (Karr \& Chu, 1999). These traits or metrics have demonstrated to be efficient for ecological assessment in running waters, ponds and lakes (Johnson, 1998; Blocksom et al., 2002; Menetrey et al., 2005; Solimini et al. 2008; Trigal et al. 2009). In this regard, certain questions arise: do metrics have the same informative value for methods of ordination as species data itself? Is species information too condensed in metrics? Both our NMDS ordination and the MRPP test statistics demonstrated comparable patterns of data dots and a high discriminatory power for both metric and species data. 
However, separation of top-down as well as bottom-up lake types on the metric level proved to be less precise than on the species level, when stress values of NMDS ordination are considered. Distances between dots of metrics data are slightly reduced in ordination space compared to species level. Admittedly, species data are composed of 50 to 80 different taxa with abundance data ranging from 1 to 70,000 individuals from which dissimilarity measures were calculated. On metrics level only nine attributes whose values ranged from 0 to 1 seem to be sufficient to achieve comparable but not identical ordination patterns.

For ecological impact studies Khan (2006) asserted that univariate statistics (e.g. Shannon-Wiener) were similar independent of their determined taxonomic levels (species, genus, and family). Macroinvertebrate studies of taxonomic resolution documented information loss solely when Chironomidae were determined on family level; in all other cases determination of the family level is sufficient (Waite et al., 2004). On the other hand, we have demonstrated that multivariate statistics and ordination of lakes types could be done accurately when species data was aggregated to metrics data. Although species level is the most accurate taxonomic level in bioindication studies, it requires a large amount of labour and operator knowledge and is time-consuming (Gomez Gesteira et al., 2003; Nahmani et al., 2006). When species data, as in our case, is translated into ecological traits and species richness, in most cases the genus or family level would be sufficient. Another benefit of metric translation was presented in the first section of our results, where single metrics calculated from species data were directly correlated to environmental parameters. As Menetry et al. (2005) have already documented the use of metrics in ecological assessment of lakes, metrics are also appropriate to screen for correlation patterns with numerous environmental parameters. Condensing species information into traits is done unconsciously by freshwater ecologists, when ecological information is related to the different species found in one sample. Metrics calculation from species data is merely a more standardised way.

By summarising this, our results indicated that type-specific benthic invertebrate assemblages are reflected both on the species level and on the metric level. Information loss from species lists to calculated metrics is marginal, while time-consuming and labo- rious determination of rare species turns out to be unnecessary.

Acknowledgments We thank Johannes Steidle for his helpful comments on the manuscript. Data collection was partly supported within a project for lake assessment using macroinvertebrate community structure by the Bund/LänderArbeitsgemeinschaft Wasser (LAWA). The submitted version of the manuscript was considerably improved, thanks to the advice of two unknown referees.

\section{References}

Alf, A., U. Braukmann, M. Marten \& H. Vobis, 1992. Biologisch-ökologische Gewässeruntersuchung-Arbeitsanleitung. Handbuch Wasser 2, Landesanstalt für Umweltschutz (Hrsg.). Karlsruhe, Loseblattsammlung.

Ali, A., J. Frouz \& R. J. Lobinske, 2002. Spatio-temporal effects of selected physio-chemical variables of water, algae and sediment chemistry on the larval community of nuisance Chironomidae (Diptera) in a natural and a man-made lake in central Florida. Hydrobiologia 470: 181-193.

Allen, A. P., T. R. Whittier, D. P. Larsen, P. R. Kaufmann, R. J. O'Connor, R. M. Hughes, R. S. Stemberger, S. S. Dixit, R. O. Brinkhurst, A. T. Herlihy \& S. G. Paulsen, 1999. Concordance of taxonomic composition patterns across multiple lake assemblages: effects of scale, body size, and land use. Canadian Journal of Fisheries and Aquatic Sciences 65: 2029-2040.

Allott, N., G. Free, K. Irvine, P. Mills, T. E. Mullins, J. J. Bowman, W. S. T. Champ, K. J. Clabby \& M. L. McGarrigle, 1998. Land use and aquatic systems in the Republic of Ireland. In Giller, P. S. (ed.), Studies in Irish Limnology. Marine Institute, Dublin: 1-18.

AQEM consortium, 2002. Manual for the application of the AQEM method. A comprehensive method to assess European streams using benthic macroinvertebrates, developed for the purpose of the Water Framework Directive. Version 1.0, February 2002. Fortführung im EU-Projekt Euro-Limpacs (www.eurolimpacs.ucl.ac.uk).

Baier, B. \& A. Zenker, 2005. Bewertungsverfahren für Makrozoobenthos in stehenden Gewässern. Limnologie aktuell 11: 121-136.

Barton, D. R., 1988. Distribution of some common invertebrates in nearshore Lake Erie, with emphasis on depth and type of substratum. Journal of Great Lakes Research 14: 34-43.

Beaty, S. R., K. Fotino \& A. Hershey, 2006. Distribution and growth of benthic macroinvertebrates among different patch types of the littoral zones of two arctic lakes. Freshwater Biology 51: 2347-2361.

Blocksom, K. A., J. P. Kurtenbach, D. J. Klemm, F. A. Fulk \& S. M. Cormier, 2002. Development and evaluation of the lake macroinvertebrate integrity index (LMI) for New Jersey lakes and reservoirs. Environmental Monitoring and Assessment 77: 311-333.

Böhmer, J., C. Rawer-Jost \& A. Zenker, 2004. Multimetric assessment of data provided by water managers from 
Germany: assessment of several different types of stressors with macrozoobenthos communities. Hydrobiologia 516: 215-228.

Brodersen, K. P., P. C. Dall \& C. Lindegaard, 1998. The fauna in the upper stony littoral of Danish lakes: macroinvertebrates as trophic indicators. Freshwater Biology 39: 577-592.

Clarke, K. R., 1993. Non-parametric multivariate analysis of changes in community structure. Australian Journal of Ecology 18: 117-143.

Clarke, K. R. \& R. M. Warwick, 2001. Change in marine communities: an approach to statistical analysis and interpretation, 2nd ed. PRIMER-E, Plymouth, UK.

Collier, K. J., 2008. Temporal patterns in the stability, persistence and condition of stream macroinvertebrate communities: relationships with catchment land-use and regional climate. Freshwater Biology 53: 603-616.

Declerck, S., J. Vandekerkhove, L. Johansson, K. Muylaert, J. M. Conde-Porcuna, K. Van, C. der Gucht, T. PerezMartinez, K. Lauridsen, G. Schwenk, W. Zwart, J. Rommens, E. Lopez-Ramos, W. Jeppesen, L. Vyverman, L. Brendonck \& L. De Meester, 2005. Multi-group biodiversity in shallow lakes along gradients of phosphorus and water plant cover. Ecology 86: 1905-1915.

Dinsmore, W. P., G. J. Scrimgeour \& E. E. Prepas, 1999. Empirical relationships between profundal macroinvertebrate biomass and environmental variables in boreal lakes of Alberta, Canada. Freshwater Biology 41: 91100.

Füreder, L., R. Ettinger, A. Boggero, B. Thaler \& H. Thies, 2006. Macroinvertebrate diversity in Alpine lakes: effects of altitude and catchment properties. Hydrobiologia 562: 123-144.

Garcia-Criado, F. \& C. Trigal, 2005. Comparison of several techniques for sampling macroinvertebrates in different habitats of a North Iberian pond. Hydrobiologia 545: 103-115.

Gomez Gesteira, J. L., J. C. Dauvin \& M. Salvande Fraga, 2003. Taxonomic level for assessing oil spill effects on soft-bottom sublittoral benthic communities. Marine Pollution Bulletin 46: 562-572.

Haase, P. \& A. Sundermann, 2004. Standardisierung der Erfassungs- und Auswertungsmethoden von Makrozoobenthosuntersuchungen in Fliessgewässern. Report for the Länderarbeitsgemeinschaft Wasser (www.fliessgewässe rbewertung.de).

Hale, P. \& B. Rippey, 2002. The ecological assessment of lakes in Nothern Ireland. ThemaNord 655: 57-64.

Hämäläinen, H., H. Luotonen, E. Koskenniemi \& P. Liljaniemi, 2003. Inter-annual variation in macroinvertebrate communities in a shallow forest lake in eastern Finland during 1990-2001. Hydrobiologia 506: 389-397.

Heatherly, T., M. R. Whiles, D. Knuth \& J. E. Garvey, 2005. Diversity and community of littoral zone macroinvertebrates in Southern Illinois reclaimed surface mine lakes. American Midland Naturalist 154: 67-77.

Heino, J., 2000. Lentic macroinvertebrate assemblages structure along gradients in spatial heterogeneity, habitat size, and water chemistry. Hydrobiologia 418: 229-242.

Hering, D., C. Meier, C. Rawer-Jost, C. K. Feld, R. Biss, A. Zenker, A. Sundermann, S. Lohse \& J. Böhmer, 2004. Assessing streams in Germany with benthic invertebrates: selection of candidate metrics. Limnologica - Ecology and Management of Inland Waters 34: 398-415.

Hrabik, T. R., B. K. Greenfield, D. B. Lewis, A. I. Pollard, K. A. Wilson \& T. K. Kratz, 2005. Landscape-scale variation in taxonomic diversity in four groups of aquatic organisms: the influence of physical, chemical, and biological properties. Ecosystems 8: 301-317.

Illies, J., 1978. Limnofauna Europaea. Gustav Fischer Verlag, Stuttgart.

Johnson, R. K., 1998. Spatiotemporal variability of temperate lake macroinvertebrate communities: detection of impact. Ecological Applications 8: 61-70.

Johnson, R. K., 2003. Development of a prediction system for lake stony-bottom littoral macroinvertebrate communities. Archiv für Hydrobiologie 158: 517-570.

Johnson, R. K. \& W. Goedkoop, 2002. Littoral macroinvertebrate communities: spatial scale and ecological relationships. Freshwater Biology 47: 1840-1854.

Karr, J. R. \& E. W. Chu, 1999. Restoring life in running waters: better biological monitoring. Island Press, Washington, DC.

Khan, S. A., 2006. Is species level identification essential for environmental impact studies? Curr Sci 91: 29-34.

Kolada, A., H. Soszka, D. Cydzik \& M. Golub, 2005. Abiotic typology of Polish lakes. Limnologica 35: 145-150.

Lafrancois, B. M., D. M. Carlisle, K. R. Nydick, B. M. Johnson \& J. S. Baron, 2003. Environmental characteristics and benthic invertebrate assemblages in Colarado mountain lakes. Western North American Naturalist 63: 137-154.

Lindegaard, C., 1992. Zoobenthos ecology of Thingvallavatn: vertical distribution, abundance, population dynamics and production. Oikos 4: 257-304.

Mathes, J., G. Plambeck \& J. Schaumburg, 2005. Die Typisierung der Seen in Deutschland zur Umsetzung der E.G-Wasserrahmenrichtlinie. Limnologie Aktuell 11: 28-36.

McCune, B. \& J. B. Grace, 2002. Analysis of Ecological Communities. MjM Software Design, Gleneden Beach, OR.

McCune, B. \& M. J. Mefford, 1999. PC-ORD. Multivariate Analysis of Ecological Data, Version 4. MjM Software Design, Gleneden Beach, OR.

McGarigal, S., S. Cushman \& S. Stafford, 2000. Multivariate Statistics for Wildlife and Ecology Research. Springer Verlag Publishers, New York, USA.

Menetrey, N., L. Sager, B. Oertli \& J. B. Lachavanne, 2005. Looking for metrics to assess the trophic state of ponds. Macroinvertebrates and amphibians. Aquatic Conservation: Marine and Freshwater Ecosystems 15: 653-664.

Mielke, P. W. Jr., 1984. Meteorological applications of permutation techniques based on distance functions. In Krishnaiah, P. R. \& P. K. Sen (eds), Handbook of Statistics, Vol. 4. Elsevier Science Publishers, Amsterdam: 813-830.

Moog, O., A. Schmidt-Kloiber, T. Ofenböck \& J. Gerritsen, 2004. Does the ecoregion approach support the typological demands of the EU 'Water Framework Directive'? Hydrobiologia 516: 21-33.

Moss, B., D. Stephen, C. Alvarez, E. Becares, W. van de Bund, S. E. Collings, E. van Donk, E. de Eyto, T. Feldmann, C. Fernández-Aláez, M. Fernández-Aláez, R. J. M. Franken, F. Garcìa-Criado, E. M. Gross, M. Gyllström, L. A. 
Hansson, K. Irvine, A. Järvalt, J. P. Jensen, E. Jeppesen, T. Kairesalo, R. Kornijow, T. Krause, H. Künnap, A. Laas, E. Lille, B. Lorens, H. Luup, M. R. Miracle, P. Nõges, T. Nõges, M. Nykänen, I. Ott, W. Peczula, E. T. H. M. Peeters, G. Phillips, S. Romo, V. Russell, J. Salujõe, M. Scheffer, K. Siewertsen, H. Smal, C. Tesch, H. Timm, L. Tuvikene, I. Tonno, T. Virro, E. Vicente \& D. Wilson, 2003. The determination of ecological status in shallow lakes - a tested system (ECOFRAME) for implementation of the European Water Framework Directive. Aquatic Conservation: Marine and Freshwater Ecosystems 13: 507-549.

Muxika, I., A. Borja \& J. Bald, 2007. Using historical data, expert judgement and multivariate analysis in assessing reference conditions and benthic ecological status, according to the European Water Framework Directive. Marine Pollution Bulletin 55: 16-29.

Nahmani, J., P. Lavelle \& J. P. Rossi, 2006. Does changing the taxonomical resolution alter the value of soil macroinvertebrates as bioindicators of metal pollution? Soil Biology and Biochemistry 38: 385-396.

Nykänen, M., T. Kairesalo, S. Mäkelä, E. Huitu, P. Ala-Opas \& J. Mannio, 2005. A typology and classification system for Finnish lakes: applicability of the ECOFRAME scheme. Boreal Environmental Research 10: 159-179.

Rennie, M. D. \& L. J. Jackson, 2005. The influence of habitat complexity on littoral invertebrate distributions: patterns differ in shallow prairie lakes with and without fish. Canadian Journal of Fisheries and Aquatic Science 62: 2088-2099.

Resh, D. J. \& T. C. Unzicker, 1975. Water quality monitoring and aquatic organisms: importance of species identification. Journal of Water Pollution Control Federation 47: 9-19.

Rippey, B., S. Doe, Y. McElaney, M. Neale, P. Hale \& V. Crone, 2002. Establishing reference conditions for phytoplankton, macrophytes and littoral macroinvertebrates in lakes. ThemaNord 566: 82-85.

Robinson, C. T. \& C. Jolidon, 2005. Leaf breakdown and the ecosystem functioning of alpine streams. Journal of the North American Benthological Society 24: 495-507.

Solimini, A. G., M. Bazzanti, A. Ruggiero \& G. Carchini, 2008. Developing a multimetric index of ecological integrity based on macroinvertebrates of mountain ponds in central Italy. Hydrobiologia 597: 109-123.
Stendera, S. E. S. \& R. K. Johnson, 2005. Additive partitioning of aquatic invertebrate species diversity across multiple spatial scales. Freshwater Biology 50: 1360-1375.

Stoffels, R. J., K. R. Clarke \& G. P. Closs, 2005. Spatial scale and benthic community organisation in the littoral zones of large oligotrophic lakes: potential for cross-scale interactions. Freshwater Biology 50: 1131-1145.

Studinski, J. M. \& S. A. Grubbs, 2007. Environmental factors affecting the distribution of aquatic invertebrates in temporary ponds in Mammoth Cave National Park, Kentucky, USA. Hydrobiologia 575: 211-220.

Sundermann, A., S. Lohse, L. A. Beck \& P. Haase, 2007. Key to the larval stages of aquatic true flies (Diptera), based on the operational taxa list for running waters in Germany. Annales de Limnologie - International Journal of Limnology 43: 61-74.

Tolonen, K. T., H. Hämäläinen, I. J. Holopainen \& J. Karjalainen, 2001. Influences of habitat type and environmental variables on littoral macroinvertebrate communities in a large lake system. Archiv für Hydrobiologie 152: 39-67.

Trigal, C., F. Garcìa-Criado \& C. Fernández-Aláez, 2006. Among-habitat and temporal variability of selected based metrics in a Mediterranean shallow lake (NW Spain). Hydrobiologia 563: 371-384.

Trigal, C., F. Garcìa-Criado \& C. Fernández-Aláez, 2009. Towards a multimetric index for ecological assessment of Mediterranean flatland ponds: the use of macroinvertebrates as bioindicators. Hydrobiologia 618: 109-123.

Van de Meutter, F., R. Stoks \& L. De Meester, 2005. The effect of turbidity state and microhabitat on macroinvertebrate assemblages: a pilot study of six shallow lakes. Hydrobiologia 542: 379-390.

Waite, I. R., A. T. Herlihy, D. P. Larsen, N. S. Urquhart \& D. J. Klemm, 2004. The effects of macroinvertebrate taxonomic resolution in large landscape bioassessments: an example from the Mid-Atlantic Highlands, USA. Freshwater Biology 49: 474-489.

White, J., 2001. The potential use of littoral macroinvertebrates in the assessment of lake water quality. Internationalen Vereinigung für Theoretische und Angewandte Limnologie, Verhandlungen 27: 3527-3532.

White, J. \& K. Irvine, 2003. The use of littoral mesohabitats and their macroinvertebrate assemblages in the ecological assessment of lakes. Aquatic Conservation Marine and Freshwater Ecosystems 13: 331-351. 